\title{
Assessment of acceptability and ease of use of atovaquone/proguanil medication in subjects undergoing malaria prophylaxis
}

\author{
$\checkmark$ Nicosia' \\ Giorgio Colombo² \\ M Consentino' \\ S Di Matteo² \\ F Mika' \\ S De Sanctis' \\ $S$ Ratti ${ }^{2}$ \\ Marta Vinci ${ }^{2}$ \\ 'Saipem Medical Dept. San Donato \\ Milanese, Italy; ${ }^{2}$ S.A.V.E. Studi Analisi \\ Valutazioni Economiche, Milano, Italy
}

Correspondence: Giorgio L Colombo

S.A.V.E. Studi Analisi Valutazioni

Economiche, Milano, Italy

Tel +392 485I 9230

Fax +39248198430

Email giorgio.colombo@savestudi.it

\begin{abstract}
Objective: International travelers from non-endemic areas are at high risk of contracting malaria due to their lack of immunity. Prevention is therefore of outmost importance and is achieved through effective and safe chemoprophylaxis, which reduces the risk of fatal disease. Among the various antimalarial drugs available, the synergistic combination of atovaquone and proguanil (A/P) (Malarone ${ }^{\circledR}$; Glaxo-SmithKline) has proven a valuable option in terms of effective protection against chloroquine and multi-drug resistant falciparum malaria, safety, tolerability, and ease of use, thus favoring compliance. The purpose of the present study was to assess acceptability and ease of use of A/P chemoprophylaxis in a population of employees of the oil industry bound to malarious areas. Particular attention was paid to treatment adherence.
\end{abstract}

Methods: A survey was conducted on a sample of 700 employees on A/P chemoprophylaxis. Demographic data and specific information on $\mathrm{A} / \mathrm{P}$ treatment were collected by means of a 16-item questionnaire administered immediately before departure. All questionnaires returned were then entered into a database and statistically analyzed.

Results: Both habitual and first-time travelers showed good adherence to A/P chemoprophylactic regimen. In general, only few adverse side-effects were reported, none of which were serious. Travelers with previous experience of other antimalarials stated A/P prophylaxis had proven advantageous due to fewer adverse reactions, better condition of administration, and better sense of protection compared with other available treatments.

Keywords: atovaquone and proguanil, Malarone, malaria prophylaxis, prevention, compliance

\section{Introduction}

Each year an estimated 50 million travelers visit malaria endemic areas (Schlagenhauf et al 2003) and 10,000-30,000 of them fall ill with malaria after returning home (Lobel and Kozarsky 1997; WHO 2008). This imported malaria, which represents an important public health problem with a high mortality rate (Muentener et at 1999), can be easily treated if diagnosed promptly, and it follows a serious course in only about $12 \%$ of individuals (Croft 2000).

The risk of infection varies considerably, depending on the degree of endemicity, the duration of stay, individual behavior, and preventive measures taken (Simons et al 2005). Risk is especially high in tropical Africa, where $80 \%-95 \%$ of infections are caused by Plasmodium falciparum (Steffen et al 2003), the most serious form. Most cases of falciparum malaria occur because of poor adherence to or complete failure to use chemoprophylaxis, combined with failure to take adequate precautions against mosquito bites (WHO 2008). 
Malaria control must be an essential part of health care programs provided by companies operating abroad in malarious areas. This is especially important considering that travelers from malaria-free regions going to endemic areas are highly vulnerable as they have little or no immunity, and are often exposed to delayed or wrong diagnosis when returning to their home country (WHO 2007).

Many companies have in-house medical departments providing the necessary assistance. Italian-based Saipem, a subsidiary of the Eni Group, is a case in point. In compliance with Italian law 626/94, the company has implemented a specific program for the prevention and control of malaria in the case of workers traveling to or residing in high risk endemic areas. Besides receiving pretravel educational materials and medical advice, Saipem's personnel are offered chemoprophylactic treatment with atovaquone and proguanil hydrochloride (Malarone ${ }^{\circledR}$; Glaxo-SmithKline) as effective chemoprophylactic regimen appropriate for subjects bound to malaria-endemic destinations. The fixed-dose combination of atovaquone and proguanil (A/P) has been reported to be highly effective for prophylaxis of malaria caused by $P$. falciparum (Shanks et al 1998; Boggild et al 2007) having an excellent safety profile during both prophylaxis and treatment courses (Boggild et al 2007).

In the case of individuals undergoing malaria prophylaxis while on duty, it is important that the treatment chosen has no negative effects that may interfere with their performance With respect to this, the choice of $\mathrm{A} / \mathrm{P}$ appears to be more advantageous compared to other antimalarials such as mefloquine and chloroquine for which severe neuropsychiatric disturbances have been reported in approximately 1 in 10,000 travelers (WHO 2008).

The present study is a questionnaire-based survey that was conducted on a sample of healthy travelers to remote worksites in malarious areas. The aim was to obtain some insights into $\mathrm{A} / \mathrm{P}$ compliance in the attempt to acquire realworld data on the acceptability and tolerability of A/P treatment from the traveler's point of view.

\section{Participants and methods}

A total of 700 Saipem's healthy employees (643 males and 57 females) traveling to malaria-endemic areas (Nigeria, Republic of the Congo, Angola) in the period from January 2007 to November 2007 were eligible for inclusion in the study. Duration of trip was 7 days on average.

Subjects were consecutively enrolled from a larger group of Saipem's employees who voluntarily agreed to participate in the study. Just before departure, all subjects underwent clinical examination and referred to the Saipem medical department where they received pretravel advice on appropriate measures of individual protection, chemoprophylaxis, and treatment. In concomitance with the counseling, they were administered a paper questionnaire by Saipem's travel medicine specialist with the aim of gathering data on the use, management, and effects of A/P chemoprophylaxis.

The questionnaire, which was provided with detailed instructions to ensure accurate completion, consisted of 16 questions to be entered after departure from the malarious area. The information requested regarded demographic data (age, sex, education), information on personal knowledge of malaria prevention/chemoprophylaxis, and possible use of antimalarial drugs in the past. The second part included questions on A/P chemoprophylaxis: ease of use, adherence to the prescribed regimen, and experience of adverse side-effects.

All 700 questionnaires were entered into a database and analyzed. Statistical analysis was performed using Student's t-test to compare average data of quantitative variables between patients who had either already traveled or were traveling for the first time as Saipem's employees to a malaria-endemic area. Statistical significance of differences in distribution frequency was tested by chi-square test (Pearson) and analysis of contingency tables. A p value of $<0.05$ was considered to be statistically significant. Analysis was carried out using statistical package SPSS 10.0 (SPSS Inc. Chicago).

\section{Results}

All 700 travelers completed the questionnaires in all their parts for a response rate of $100 \%$ and delivered them to Saipem's medical department on their return. Of these, $85 \%$ were returned in electronic form and the remainder $(15 \%)$ on paper. Ninety percent of the respondents were habitual travelers, whereas $10 \%$ were on their first visit to a malarious region as employees of Saipem. Most were male $(92 \%)$ in both groups. Mean age was 38.3 years in the group of habitual travelers and 30.7 in those traveling for the first time. Most had a high educational background: tertiary school $(22 \%)$ or first degree or post-degree specialization (77\%). Compliance was extremely high as $99.6 \%$ of subjects adhered to the A/P chemoprophylactic regimen, which required 1 adult tablet (atovaquone $250 \mathrm{mg}+$ proguanil hydrochloride $100 \mathrm{mg}$ ) daily beginning 1-2 days before exposure, throughout exposure, and continuing 7 days 
after departure from the malaria-endemic area (CDC 2007). Only 3 individuals were not compliant, and the reason for failing to adhere was explained as low perception of malaria exposure risk (Table 1).

Of the habitual travelers, most $(88.5 \%)$ had used chemoprophylaxis with $\mathrm{A} / \mathrm{P}$ on previous occasions (mean number of times 2.4 ) and for only 72 of them (11.5\%) this was the first time they had experienced A/P prophylaxis. Nearly all habitual travelers (96.5\%) had taken other antimalarials on past occasions, namely mefloquine (67.7\%), proguanil (12.6\%), chloroquine (12.5\%), and doxycycline $(7.3 \%)$. Among first-time travelers only mefloquine $(\mathrm{n}=30 ; 100 \%)$ was indicated as medication previously used as an antimalarial (Table 2).

When asked about the reason for choosing $\mathrm{A} / \mathrm{P}$ as antimalarial chemoprophylaxis, $44 \%$ of the habitual travelers and $59 \%$ of first-time travelers responded that they were following medical advice. For an equal proportion in both groups $(23 \%)$ the reason was because they were aware of the regimen benefits. Twenty-two percent of the habitual travelers compared with about $10 \%$ in the other group admitted having chosen $\mathrm{A} / \mathrm{P}$ for the fewer adverse sideeffects. Better sense of protection against the disease was the answer chosen by $10 \%$ of habitual travelers against $8 \%$ of first-time travelers (Figures 1 and 2).

When asked to highlight possible differences with other antimalarial drugs, the group of habitual travelers generally declared having experienced much fewer $(85.2 \%)$ or rather fewer (14.8\%) adverse side-effects. Condition of administration was generally well accepted, being very easy $(5.5 \%)$ and rather easy $(94.5 \%)$ to manage. In terms of sense of protection against the disease, most had felt rather $(77.2 \%)$ and much $(22.8 \%)$ more protected if compared with previous other prophylactic treatments (Table 3). The most common adverse reaction was abdominal pain in both habitual travelers $(n=61)$ and first-time travelers $(n=24)$, followed by few cases of headache and nausea. No serious adverse reactions were reported (Table 4).

\section{Discussion}

Past studies, recently reviewed by Boggild et al (2007) have proved A/T efficacy and optimum safety profile, considering also its advantage over other antimalarial drugs in terms of efficacy against multidrug-resistant $P$. falciparum malaria.

Our aim, however, was to assess the impact of $\mathrm{A} / \mathrm{P}$ chemoprophylaxis in actual conditions of usage with particular attention to ease of use, individual capacity to

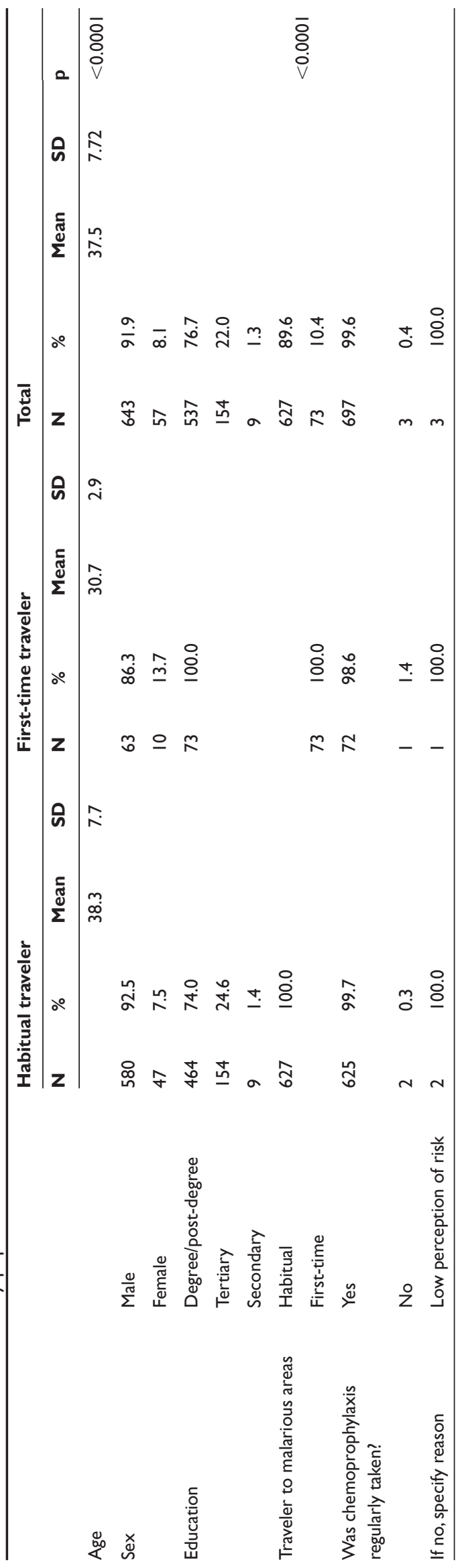


Table 2 History of chemoprophylaxis in study population

\begin{tabular}{|c|c|c|c|c|c|c|c|c|c|c|c|c|c|c|}
\hline & & \multicolumn{4}{|c|}{ Habitual traveler } & \multicolumn{4}{|c|}{ First-time traveler } & \multicolumn{5}{|c|}{ Total } \\
\hline & & $\mathbf{N}$ & $\%$ & Mean & SD & $\mathbf{N}$ & $\%$ & Mean & SD & $\mathbf{N}$ & $\%$ & Mean & SD & $\mathbf{p}$ \\
\hline Is this the first time & No & 555 & 88.5 & & & 73 & 100.0 & & & 555 & 79.3 & & & $<0.0001$ \\
\hline you used $A / P$ ? & Yes & 72 & 11.5 & & & & & & & 145 & 20.7 & & & \\
\hline $\begin{array}{l}\text { If no, how many times did } \\
\text { you use } A / P \text { in the past? }\end{array}$ & & & & 2.4 & 1.28 & & & & & & & 2.4 & 1.28 & \\
\hline $\begin{array}{l}\text { Did you use other } \\
\text { antimalarials other than }\end{array}$ & Yes & 605 & 96.5 & & & 30 & 42.3 & & & 635 & 91.0 & & & $<0.0001$ \\
\hline $\mathrm{A} / \mathrm{P}$ in previous occasions? & No & 22 & 3.5 & & & $4 I$ & 57.8 & & & 63 & 9.0 & & & \\
\hline \multirow[t]{4}{*}{ If yes, specify which ones } & Mefloquine & 409 & 67.7 & & & 30 & 100.0 & & & 626 & 68.7 & & & \multirow{4}{*}{$<0.0001$} \\
\hline & Proguanil & 76 & 12.6 & & & & & & & 111 & 12.2 & & & \\
\hline & Chloroquine & 76 & 12.5 & & & & & & & 110 & 12.1 & & & \\
\hline & Doxycycline & 44 & 7.3 & & & & & & & 64 & 7.0 & & & \\
\hline
\end{tabular}

Abbreviation: $\mathrm{A} / \mathrm{P}$, atovaquone/proguanil combination.

comply with the regimen prescribed, and experience of adverse reactions. Of note, the survey was carried out on a considerably large sample $(n=700)$, if compared with available studies, whose samples do not usually exceed 150 included subjects.

Our findings are in line with other published data for safety and tolerability (Shanks et al 1998; Schlagenhauf et al 2003; Simons et al 2005), in that A/P prophylaxis was well tolerated, with only mild to moderate adverse side-effects - namely, those reported by the manufacturer - and no serious adverse reactions. We may speculate that the lack of important adverse reactions may have favored better adherence to the regimen prescribed as shown by the high proportion of travelers who reported regular chemoprophylaxis. As noted in a number of studies including the paper by Franco-Paredes et al (2006), non-adherence to

\section{Habitual traveler}

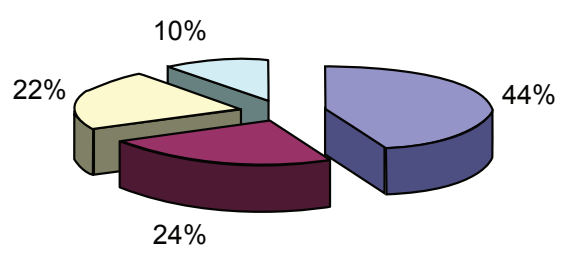

\begin{tabular}{ll}
\hline Medical advice & $\square$ Awareness of benefits \\
$\square$ Fewer adverse side-effects & $\square$ Higher sense of protection
\end{tabular}

Figure I Reasons underlying preference for atovaquone/proguanil chemoprophylaxis in habitual travelers. chemoprophylactic regimens is in fact frequently secondary to drug side effects. Furthermore, in a study by McKeage and Scott (2003) fewer recipients of A/P discontinued treatment because of adverse events than individuals receiving chloroquine plus proguanil or mefloquine. Most importantly, no A/P-related neuropsychiatric disturbances were reported. These findings reflect those of previous studies demostrating a lower frequency of neuropsychiatric adverse events with $\mathrm{A} / \mathrm{P}$ compared with mefloquine (Overbosch et al 2001). Considering that approximately 1 in 10,000 travelers receiving mefloquine or chloroquine prophylaxis experience severe neuropsychiatric disturbances (WHO 2008), our results suggest that A/P may be considered a valuable therapeutic option especially when treatment concerns subjects on duty where physical and mental fitness is a prerequisite for their safety (Simons et al 2005).

\section{First-time traveler}

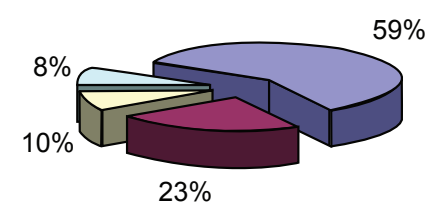

\begin{tabular}{|ll|}
\hline$\square$ Medical advice & $\square$ Awareness of benefits \\
$\square$ Fewer adverse side-effects & $\square$ Higher sense of protection
\end{tabular}

Figure 2 Reasons underlying preference for atovaquone/proguanil chemoprophylaxis in first-time travelers. 


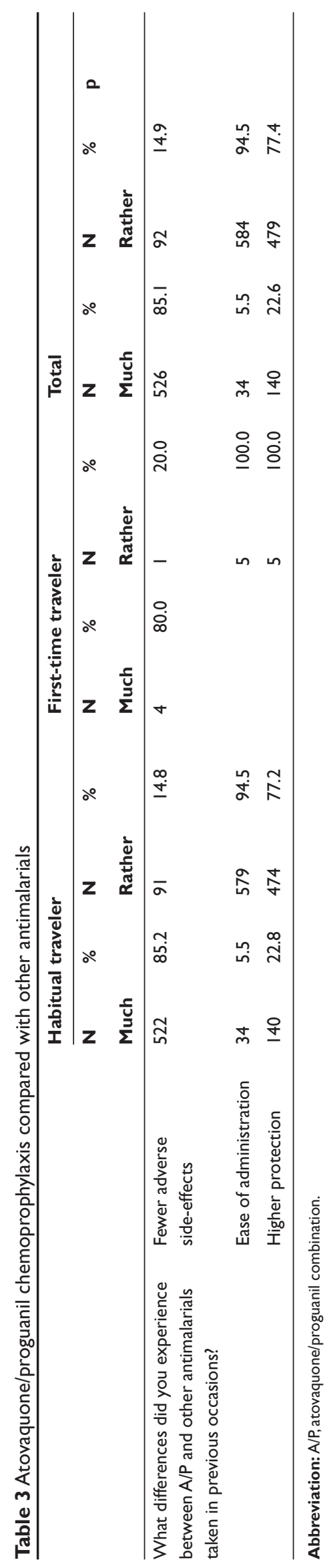

Compared with other available antimalarial drugs, prophylaxis with A/P appears to have appreciable advantages in terms of administration schedule and duration of recommended treatment. This aspect may also have favored the good level of adherence recorded. In fact, A/P prophylaxis can be started only 1-2 days before exposure and, above all, since the drug has casual prophylactic activity against the hepatic stages of $P$. falciparum (Shapiro et al 1999), it can be discontinued 7 days after departing a malarious region (Shanks et al 1999), compared with 4 weeks with other antimalarials. This more convenient dosage regimen, particularly in the post-travel period, should not be undervalued, considering that good chemoprophylaxis does reduce the risk of fatal disease (WHO 2008) especially in non-immune or semi-immune subjects when they return to their home country and that adherence rates for 4 weeks post exposure are generally low (CDC 2007).

Though it is noteworthy that the survey was conducted on a large sample, it is necessary to point out some limitations that suggest cautious interpretation of the findings observed.

Treatment adherence was found to be very high (99\%), which was probably the result of an overestimation because of the method employed. Questionnaire assessment, though widely used, has in fact some limitations because returning travelers tend to forget precise date and time of drug intake and over-report the correct regimen in an effort to please the investigator or to hide one's failure (Landry et al 2006).

As for the side effects reported, it must be noted that monitoring was focused more on acute events, since questionnaires were delivered on return from the endemic area. As a consequence, under-reporting is likely to have occurred, especially on adverse reactions that emerged after some period of time. Moreover, it was not possible to assess possible interactions with other drugs as no specific medical data were collected from the sample. A further limitation is that our study lacks a control group using a different chemoprophylaxis and that most subjects included were male.

Nonetheless, data gathered from such a large number of subjects may be helpful in providing new insights into the real acceptability of $\mathrm{A} / \mathrm{P}$ chemoprophylaxis. In the future it would be worth investigating further its good tolerability profile and more convenient dosage regimen in well-designed studies to prove their value in promoting better adherence and thus better efficacy. 
Table 4 Adverse effects experienced by travelers on atovaquone/proguanil chemoprophylaxis

\begin{tabular}{|c|c|c|c|c|c|c|c|c|c|c|c|c|c|c|}
\hline & & \multicolumn{4}{|c|}{ Habitual traveler } & \multicolumn{4}{|c|}{ First-time traveler } & \multicolumn{5}{|c|}{ Total } \\
\hline & & $\mathbf{N}$ & $\%$ & Mean & SD & $\mathbf{N}$ & $\%$ & Mean & SD & $\mathbf{N}$ & $\%$ & Mean & SD & $\mathbf{p}$ \\
\hline \multirow{4}{*}{$\begin{array}{l}\text { Specify adverse } \\
\text { side-effects, if any }\end{array}$} & Abdominal pain & 61 & 66.3 & & & 24 & 88.9 & & & 85 & 71.4 & & & \\
\hline & Headache & 14 & 15.2 & & & 2 & 7.4 & & & 16 & 13.4 & & & \\
\hline & Nausea & 14 & 15.2 & & & 1 & 3.7 & & & 15 & 12.6 & & & \\
\hline & Other & 3 & 3.3 & & & & & & & 3 & 2.5 & & & \\
\hline
\end{tabular}

\section{Disclosures}

No sources of funding were used to assist in the preparation of this paper. The authors have no conflicts of interest that are directly relevant to the content of this paper.

\section{References}

Anabwani G, Canfield CJ, Hutchinson DB. 1999. Combination atovaquone and proguanil hydrochloride vs halofantrine for treatment of acute Plasmodium falciparum malaria in children. Pediatr Infect Dis $J$, 18:456-61.

Boggild AK, Parise ME, Lewis LS, et al. 2007. Atovaquone-proguanil: report from a CDC expert meeting on malaria chemoprophylaxis (II). Am J Trop Med Hyg, 76:208-23.

[CDC] Centers for Disease Control and Prevention. 2007. Information for the Public: Prescription Drugs for Malaria [online]. Accessed 02 April 2008. URL: http://wwwn.cdc.gov/travel/contentMalariaDrugsPublic.aspx

Croft A. 2000. Extracts from "Clinical Evidence": Malaria: prevention in travelers. $B M J, 321: 154-60$.

de Alencar FE, Cerutti C, Durlacher RR, et al. 1997. Atovaquone and proguanil for the treatment of malaria in Brazil. J Infect Dis, 175:1544-7.

Franco-Paredes C, Santos-Preciado JI. 2006. Problem pathogens: prevention of malaria in travelers. Lancet Infect Dis, 6:139-49.

Landry P, Iorillo D, Darioli R, et al. 2006. Do travelers really take their mefloquine malaria chemoprophylaxis? Estimation of adherence by an electronic pillbox. $J$ Travel Med, 13:8-14.

Lobel HO, Kozarsky PE. 1997. Update on prevention of malaria for travelers. JAMA, 278:1767-71.

McKeage K, Scott L. 2003. Atovaquone/proguanil: a review of its use for the prophylaxis of Plasmodium falciparum malaria. Drugs, 63:597-623.
Muentener P, Schlagenhauf P, Steffen R. 1999. Imported malaria (1985-1995): trends and perspectives. Bull WHO, 77:560-6.

Overbosch D, Schilthuis H, Bienzle U, et al. 2001. Atovaquone-proguanil versus mefloquine for malaria prophylaxis in nonimmune travelers: results from a randomized, double-blind study. CID, 33:1015-21.

Radloff PD, Philipps J, Nkeyi M, et al. 1996. Atovaquone and proguanil for Plasmodium falciparum malaria. Lancet, 347:1511-4.

Schlagenhauf P, Tschopp A, Johnson R, et al. 2003. Tolerability of malaria chemoprophylaxis in non-immune travelers to sub-Saharan Africa: multicentre, randomised, double blind, four arm study. $B M J$, 327:1078-81

Shanks GD, Gordon DM, Klotz FW, et al. 1998. Efficacy and safety of atovaquone/proguanil as suppressive prophylaxis for Plasmodium falciparum malaria. Clin Infect Dis, 27(3):494-9.

Shapiro TA, Ranasinha CD, Kumar N, et al. 1999. Prophylactic activity of atovaquone against Plasmodium falciparum in humans. Am J Trop Med Hyg, 60:831-6.

Simons R, Valk PJL, Krul AJ. 2005. Malaria prophylaxis for aircrew: safety of atovaquone/proguanil in healthy volunteers under aircraft cabin pressure conditions. J Travel Med, 12:210-16.

Steffen R, deBernardis C, Baños A. 2003. Travel epidemiology - a global perspective. Int J Antimicrob Agents, 21:89-95.

van Riemsdijk MM, Sturkenboom MC, Ditters JM, et al. 2002. Atovaquone plus chloroguanide versus mefloquine for malaria prophylaxis: a focus on neuropsychiatric adverse events. Clin Pharmacol Ther, 72:294-301

[WHO] World Health Organization. 2007. Facts sheet N 94. [online]. Accessed 1 April 2008. URL: http://www.who.int/mediacentre/ factsheets/fs094/en/

[WHO] World Health Organization. 2008. Global Malaria Programme. International Travel and Health. Chapter 7 [online]. Accessed 1 April 2008. URL: http://www.who.int/ith/en/ 